\title{
Integrating Elements of Modern Technology into Maritime Safety
}

Prateek Rana* $3^{\text {rd }}$ B.Tech student at Indian Maritime University

Purbita Datta Majumder** $3^{\text {rd }}$ B. Tech student at Indian Maritime University

*, ** Kolkata, India

prateekrana260@gmail.com \& pdmajumder98@gmail.com

\begin{abstract}
Synopsis
A majority of the accidents on board a ship occurs due to poor knowledge of safety regulations or carelessness towards the same. As a remedy, this paper will propose ideas that include digitalization of safety procedures so as to realize the powers of visual perception of information over a paper-based one, a unique Safety Wear and Equipment Identification system and pre-board training using Virtual Reality. Interactive, touch-screen monitors, the size of usual tablets will be affixed to the walls of numerous rooms and spaces across the ship (e.g.: engine room) that will revolutionize the way safety norms are implemented. They will also have cameras, affixed. Object-recognition software, paired with these cameras will scan the image of the person, starting a task, to ensure that he/she has every necessary safety wear/equipment/tool on them, specific to the task that they are performing. Unless verified by the software, a person cannot start the job. There's a study of how this software helps to fulfil International Safety Management (ISM) CODE to a new level and how using it can help shipping companies.
\end{abstract}

Keywords- Digitalization, interactive, PPE (Personal Protective Equipment), ISM code.

\section{Introduction}

\subsection{Human Error}

A large portion of the casualties on board occur due to poor knowledge or negligence of safety rules and regulations. Despite this cause being a very prevalent one, not a lot of change has been experienced by the maritime field to combat it and help seafarers learn to be safer. There are quite a few areas on a ship that demand an engineer to perform dangerous tasks and often times, a casualty occurs because of human error i.e. either the engineer forgets/neglects certain safety precautions which includes the donning of protective equipment or has very poor knowledge of the same. From the statistics presented below, it can be clearly seen that a majority of the casualties on board a ship, occur due to human error.

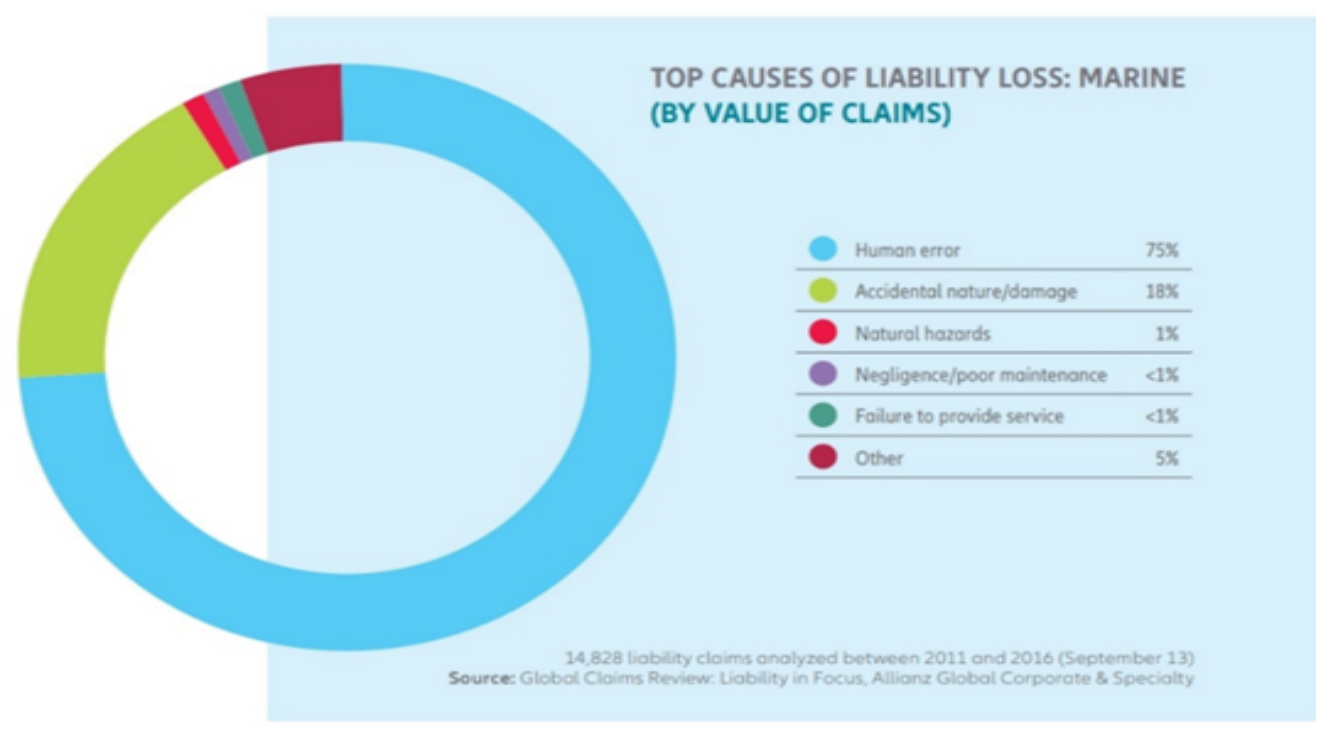

Figure 1. AGCS Safety and shipping review 2018 showing that $75 \%$ of claims are due to "Human error". 


\subsection{Visual Learning}

A large number of the procedures on a ship are still pen-and-paper based, especially those that are intimate safety regulations to the officers and cadets on board. The benefits of visual learning surpass those of contemporary methods greatly. Instead of reading about the various risks and safety precautions to be taken, if an officer/cadet can receive a concise yet vitally informative visual reminder of the same, just before embarking on a task, the information will likely remain more intact, in their minds thus making them more alert. Any confusion or misunderstanding that may arise due to someone overlooking an important piece of text or not being able to comprehend it properly will be overcome too. The integration of audio-visual aids in the process that warns seafarers of risks and corresponding safety precautions of a task is therefore a step in the right direction.

Some benefits of visual learning are listed below:

- Visuals stick in long-term memory

- Visuals speed up comprehension and transmit messages to the brain faster

- Visuals trigger emotions that, in this particular case, can push a person to become more wary of the risks being talked about.

Graphic Description

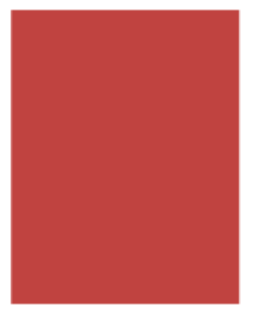

Textual Description

\author{
A plane figure with four \\ equal straight sides \\ and four right angles.
}

Figure 2. An example of how visual learning is more effective than textual learning

\subsection{Going Paperless}

While many onshore businesses have opted for the paperless route, a ship's environment may not allow for the same. But even then, going paperless or digitalizing the storage of data and information related to everyday activities, wherever possible, can prove to be advantageous. Using the monitor, a large number of paper-based activities will be reduced. Records of every individual's tasks will be stored electronically and many safety checklists will be replaced by visual instructions. Attendance and efficiency of task completion can be monitored effectively.

Some of the benefits of going paperless are:

- Increase in productivity: Electronically stored information is readily accessible to anyone who needs it which means that time spent in transit and chances of loss are cut down severely.

- Faster sharing of data: Some kinds of information may need to be shared with everyone on board and some may need to be made known to a certain number of people. Regardless, sharing this information will become much easier with electronic means.

Most seafarers are technologically savvy and any difficulty faced during the operation of the interactive monitor will easily be overcome due to the user-friendly nature of the system. 


\subsection{ISM CODE}

International Safety Management code is a part of SOLAS convention adopted in the year 1994. The code provides mandatory safety standards for a vessel irrespective of its nationality. The requirements of the ISM Code may be applied to all commercial ships over 500 GT (Gross Tonnage). An audit is to be cleared by the company (operating the vessel) and the vessel in order to receive Document Of Compliance (D.O.C.) and Safety Management Certificate (S.M.C.) respectively. Our solution will concentrate on the following sections of the code:-

1. Section 4 -The designated person(s) - A designated person ashore is appointed by the company for monitoring the safety and pollution- prevention aspects of the operation of each ship and ensuring that adequate resources and shore-based supports are applied. He/ She possess direct access to highest level of management.

2. Section 7 -DEVELOPMENT OF PLANS OR KEY SHIPBOARD OPERATIONS- A Company is supposed establish procedures, plans and instructions, including checklists as appropriate, for key shipboard operations concerning the safety of the personnel, ship and protection of the environment. The various tasks should be defined and assigned to qualified personnel.

3. Section 8 - EMERGENCY PREPAREDNESS - The Company is supposed to identify potential emergency shipboard situations, and establish procedures to respond to them.

4. Section 9- REPORTS AND ANALYSIS OF NON-CONFORMITIES, ACCIDENTS AND HAZARDOUS OCCURRENCES - The Safety Management System (SMS) should include procedures ensuring that non-conformities, accidents and analysed with the objective of improving safety and pollution prevention. The company is supposed to establish procedures for the implementation of corrective actions.

\section{Current System on-board}

A Plan Management System, for a year, is uploaded onto a ship's computer that illustrates the daily maintenance activities that need to be performed on the various machineries on a ship. The engineers are assigned tasks on a daily basis. Records are maintained on paper. An on paper risk assessment of every job is done, before someone performs the job but without any visual aids. No electronic monitoring system is present where daily tasks can be monitored for efficiency, time consumption and safety.

\section{How the new system will work?}

A combination of certain hardware parts and specialized software will enable a new system of effective monitoring to be implemented on ships. A series of monitors, similar to conventional tablets can be fitted onto the walls of many different areas on a ship such as the Engine Room, Ship office, Engine office, Bridge, alleyways, forecastle, Senior officers' rooms, Boson Store etc. These touchscreen monitors will be loaded with special software that will help run the new system and will be connected to one another by means of a LAN setup (Figure 3). Not more than 3-4 routers will be required to achieve this, since the length of an average ship is close to 300 meters. Each person can also be provided with his/ her personal tablet which can be carried everywhere with them. The accessibility to assign tasks to the rest will be to the authorized person or say higher rank officers (Figure 12). 


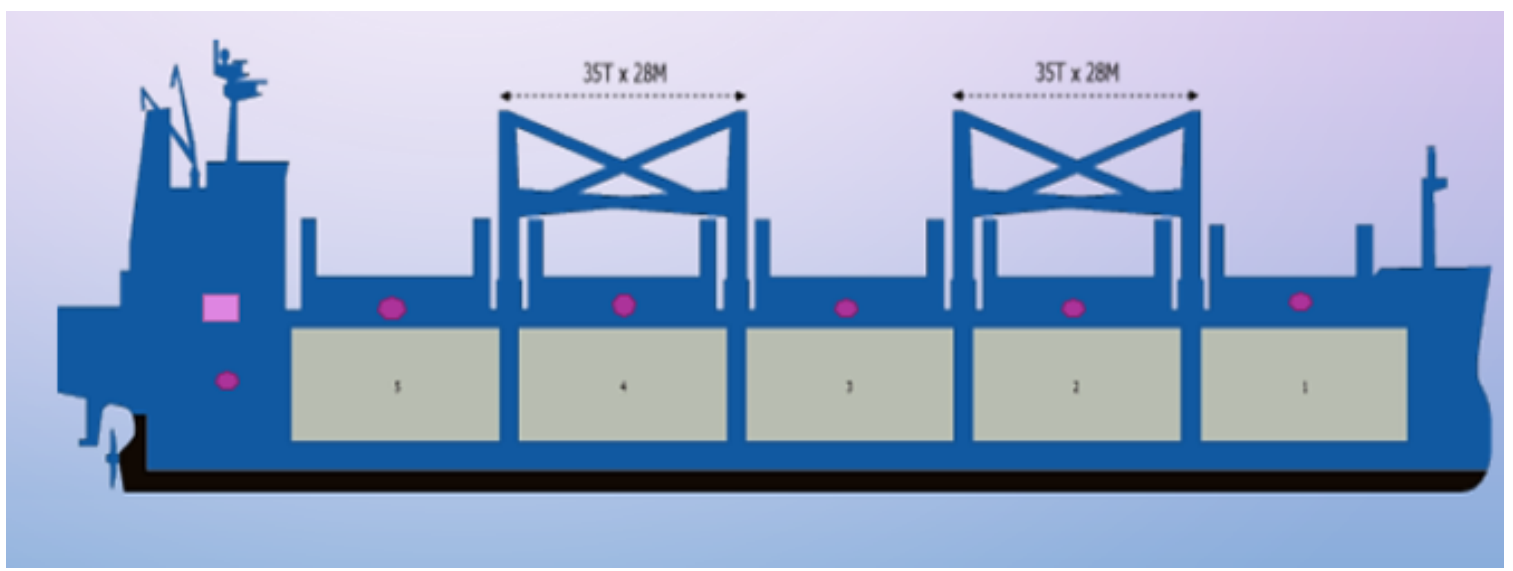

Figure 3: Positions of server $(\square)$ and routers $(\bullet)$.

The digital assigning of daily tasks to the different people on board will also be done by a select few people. Everyone on board, before the commencement of the ship's journey must register themselves with the system. This will be done by opening different offline accounts for each person through facial recognition. A camera will be attached to the "head" monitors for this purpose. Cameras will also be present with some of the other monitors, as required, to enable the functioning of another aspect of this system. Object-recognition software, paired with these cameras will scan the image of the person, starting a task, to ensure that he/she has every necessary safety wear/equipment/tool on them, specific to the task that they are performing. Unless verified by the software, a person cannot start the job.

Once a person has been recognized by the camera (through facial recognition), he/she will have to select the task from the list appearing on the device and thereafter will be reminded, visually of all the risks and corresponding safety precautions to be taken. If required, the steps needed to complete a task can be accessed as well(Figure 6). After this, the scanning of the person, to check the presence of safety equipment will be done. This whole process should not take more than 5-10 minutes. Once the job is complete, the person has to verify his/her presence once more and then finish. An option to disable the scanning and safety-briefing aspects of the system will be provided as in times of emergency, it may be wiser to not have this system active. However, this step will be taken by the senior officers/engineers/captain and will be according to their discretion. For the monitors that won't have a camera attached to them, a conventional method of using an ID and Password can be used by a person to access his/her account.

These monitors need not all have the camera setup, so costs can be reduced. Only in places where detection of safety wear is a must, is it a requirement. Apart from the engine room, there are other places such as the workshop where this camera system may be required. Say if any lathe-job, grinding job etc. has to be performed in the Workshop, then it must be confirmed that the people performing that job are wearing all the right wear and possessing all the right equipment.

\subsection{Safety Monitoring.}

To further elucidate, a single example of the functioning of this system can be taken, as described below: -

Consider a $4^{\text {th }}$ engineer has to do tasks $\mathrm{A}, \mathrm{B}$ and $\mathrm{C}$ in a day. A senior on board with the authority to assign tasks will upload the names of the tasks in the account of the $4^{\text {th }}$ engineer, in the morning. Note that all the monitors need to have a database of every task that is performed on a ship, so that the process of assigning becomes very simple. Once this is done, the engineer may prepare himself/herself for the duty and proceed to the engine room. Once there, he can login to his/her account through facial recognition and see the list of tasks he/she is expected to perform (Figure 4). After selecting, say, task A (Figure 5), a list of risks along with descriptive pictures will be presented. Following that, another detailed explanation of the corresponding safety precautions will be provided, also with visual representations (Figure 6). If the engineer needs help with the method in which to perform the task, or the steps to be taken, he/she may access that information too. However, it is not mandatory. The intimation of risks and precautions are mandatory. After this, he/she will be scanned to see whether necessary safety wear like a helmet, gloves etc. can be found on their body (Figure 8). After this, by tapping the "Start Job" option on their monitor, they can begin their task (Figure 9). Once done, they will return to the monitor and tap on "Job Completed" option (Figure 10). Any notes or comments that he/she feels is necessary for future use or for a brief description of how and what he/she did may be entered too. The camera 
will once again recognize the person standing in front of it and then finally end the record of that job. This process will be repeated for every job. In case of sudden faults occurring in machineries at odd hours, a senior engineer can assign that task from any nearby monitor that is to say that tasks can be assigned at any time of the day and whenever needed.

\subsection{Camera Software.}

The camera provided with the screen will be able to detect whether or not the engineer is wearing all the safety equipment. The software for the same can be programmed using OpenCV library and Tensorflow tool in Python. Every Object Detection Algorithm has a different way of working, but they all work on the same principle i.e. feature extraction. They extract features from the input images at hand and use those features to determine the class of the image, be it through MatLab, Open CV, Viola Jones or Deep Learning.

When the system is able to detect all the safety equipment required for a job, only then it will be allowing the engineer to perform the task. In case if the system doesn't recognize the required safety equipment for a job, the engineer will not be allowed to do the job and no record of the task being completed will be stored.

Important points to be kept in mind while developing the software: -

1. Registering all safety equipment that are used on board in the form of training data. Each safety equipment's shape/color may vary depending upon the manufacturer, so it's important to register all the different models of safety equipment that's available on a vessel.

2. A flash is to be provided to avoid any error in dim lighting.

\subsection{Communication.}

The reason why so many of these monitors were suggested to be installed in different areas on the ship was not only because of the safety monitoring aspect but also because these monitors can enhance the efficiency of communication on board. Walkie-talkies may not always be on a person. In case any urgent message needs to be sent to someone, it can be done through the system of monitors (which are all connected to one another). Everyone will have the authority to send a message but they will need to login using their ID and password or through facial recognition. However this requirement may be disabled if preferred. The person sending the message can choose which specific monitor to send the message to (Figure 11). Otherwise, the message can be sent to all the monitors together. Once a message is received by a monitor, an alarm will start sounding till a person comes and taps "Read message" on the screen. This will ensure speedy and direct communication when some information needs to urgently be conveyed. A record of all messages and replies will be stored separately by the head-monitor. No matter where a person is, he/she is sure to get the message either directly or through someone else who has seen the message.

There will also be a separate "Medical Emergency" option on the monitor (Figure 15). This option will be present in all the windows of the monitor. When a person is injured and is in need of assistance, he/she can quickly tap this option and without any delay a distress message relaying the location of the monitor (and therefore the person) can be shared. Alternately, if there is someone else present with a person who is unable to move by himself/herself, he/she can press the option to call for more help.

\section{Screens that will appear. The following images are proposed designs of selected screens that will appear during the operation of the software.}




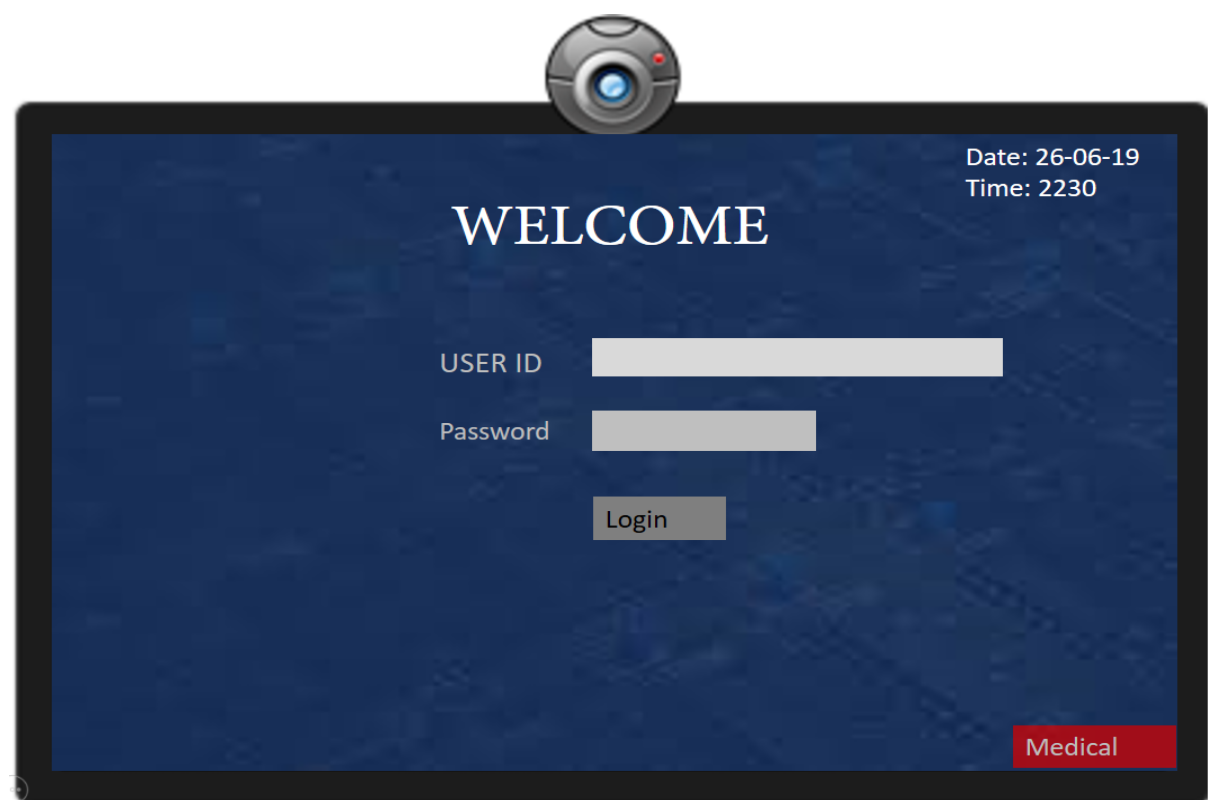

Figure 4. This image displays the method of logging in using an ID and a password. It will be utilized if somehow a camera is not present or is faulty.

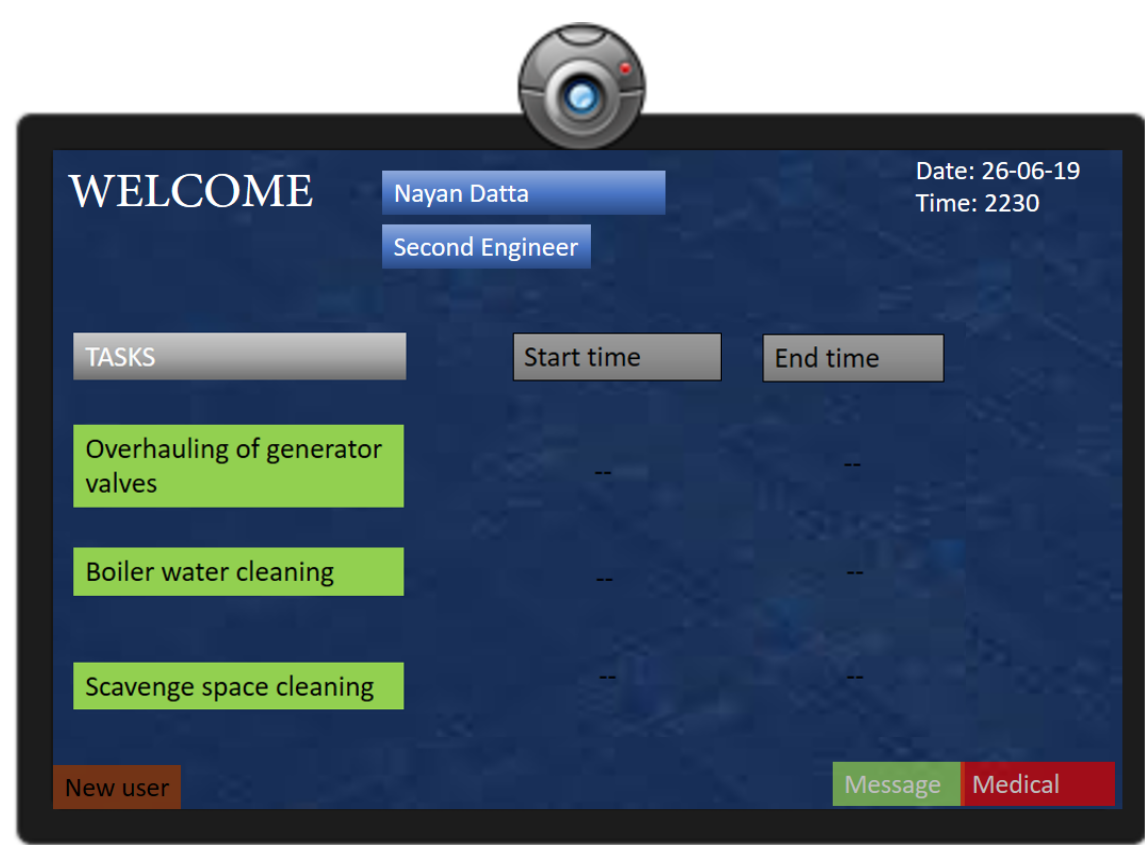

Figure 5. The officer will see his/her various tasks and will select the one that he/she has to perform at that time. 


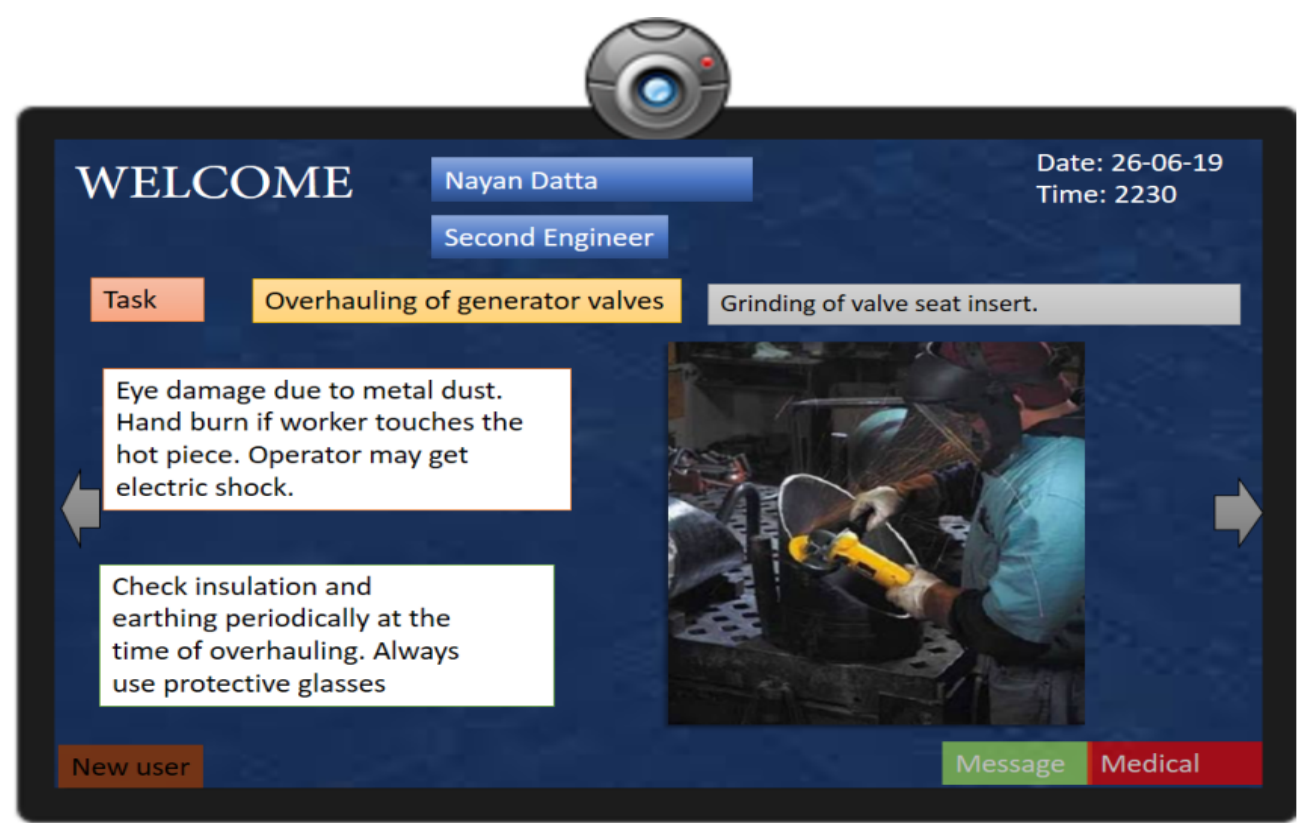

Figure 6 . The risks and safety precautions will be described along with an image to support the text. Here the risk is in the first box and the precaution in the box below it. Arrows on either side can be used to move between screens displaying different risks and precautionary measures relating to a certain task.

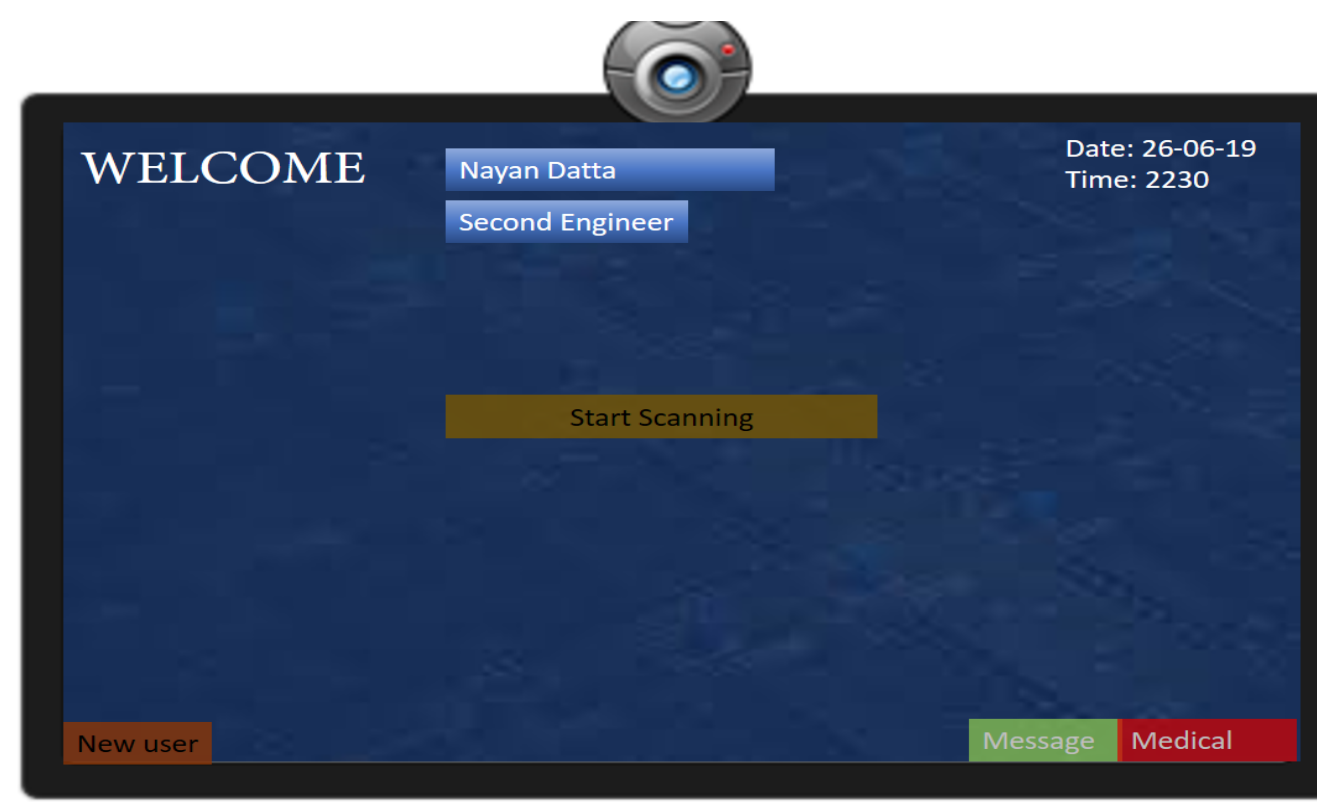

Figure 7. Once the briefing is finished, the camera scanning process can start. 


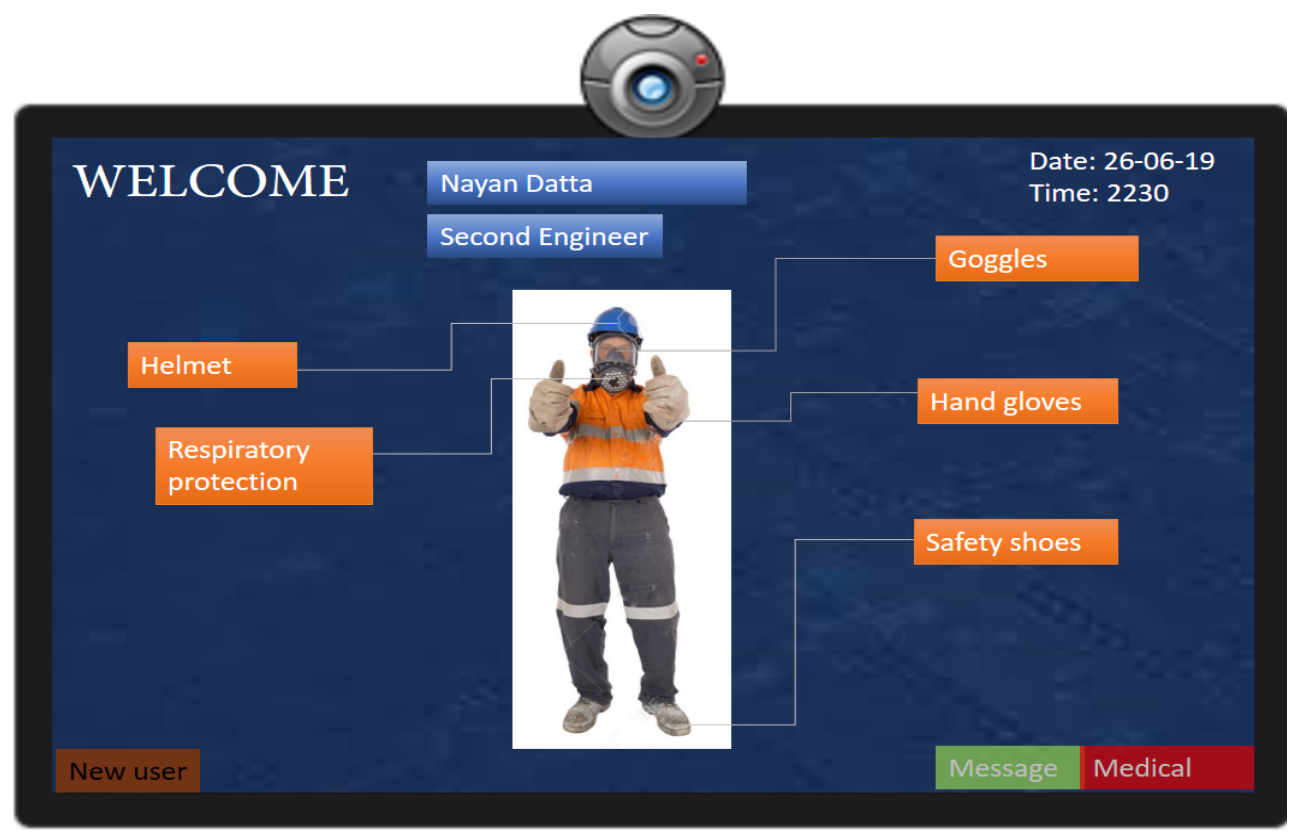

Figure 8. This is a suggestive image of what the purpose of the scanning process is. It will detect the presence of the various safety equipment on the person.

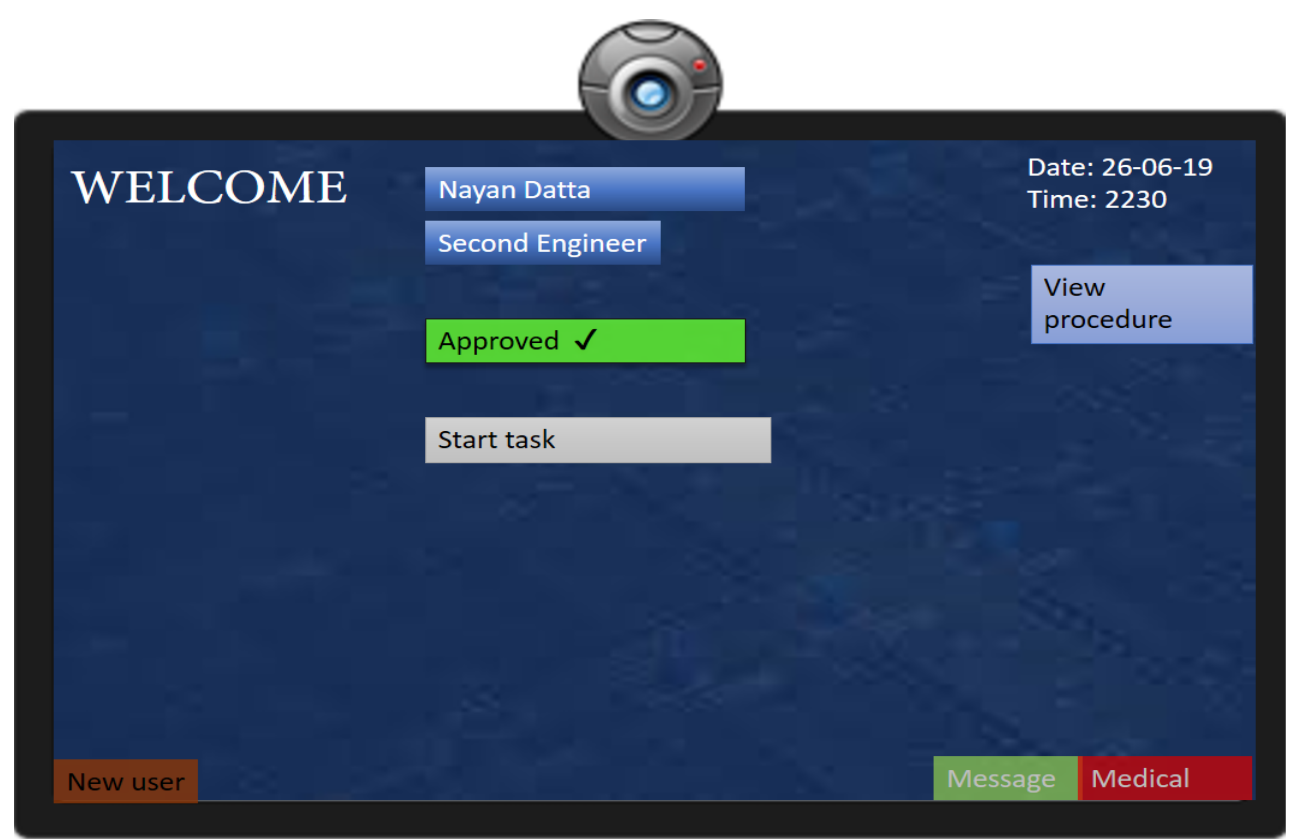

Figure 9. If every required equipment/wear is found to be on the person, he/she will then be able to start his/her task. Optionally, if the officer wants to view the steps of the procedure, he/she simply will have to select the "View procedure" option. 


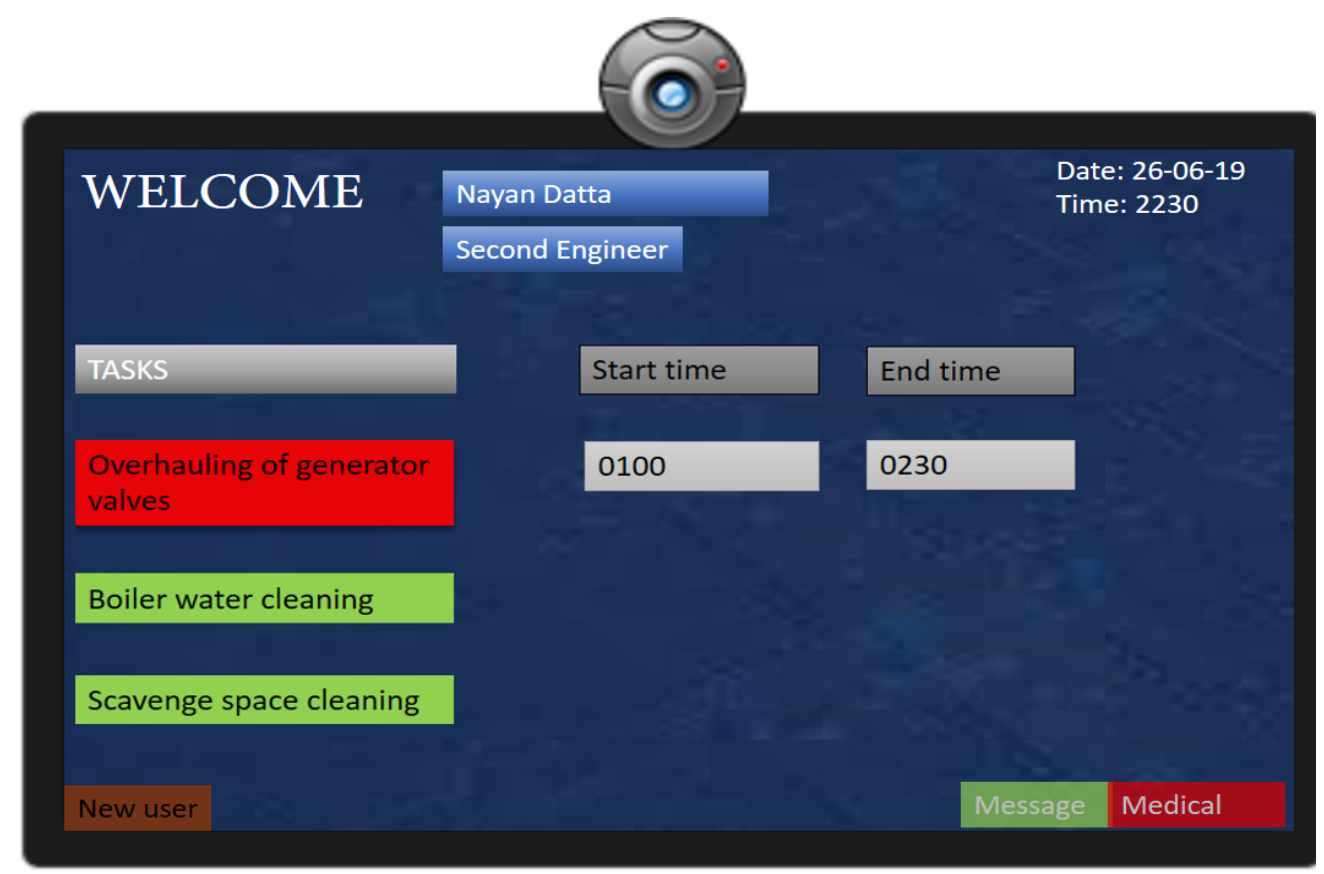

Figure 10. Once the officer ends his/her task, this screen showing the start and end times of the finished task will appear. He/she may then proceed to the next task.

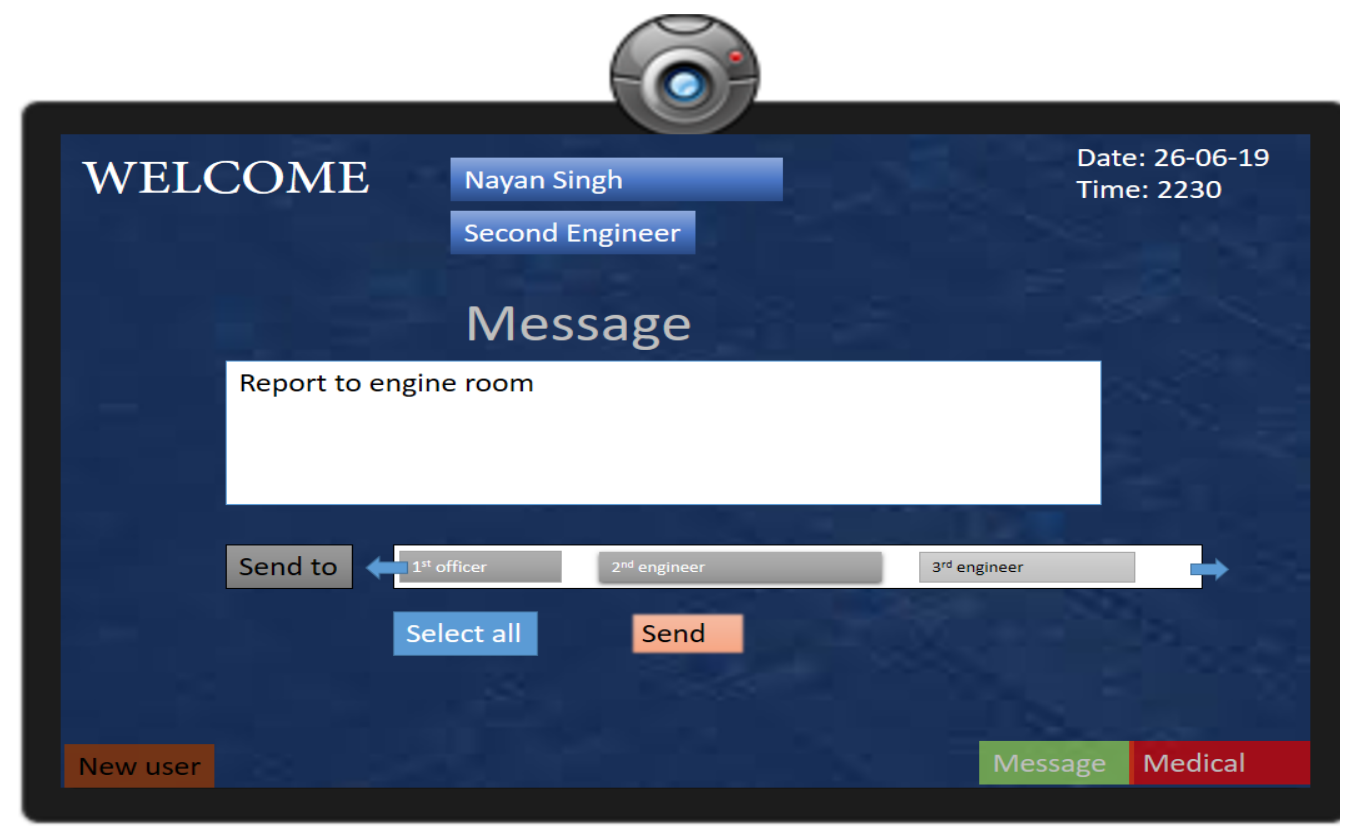

Figure 11. If a message needs to be sent urgently, the person may type in the text through an on-screen keyboard and then select the locations of the monitors that he wants to send the message to. 


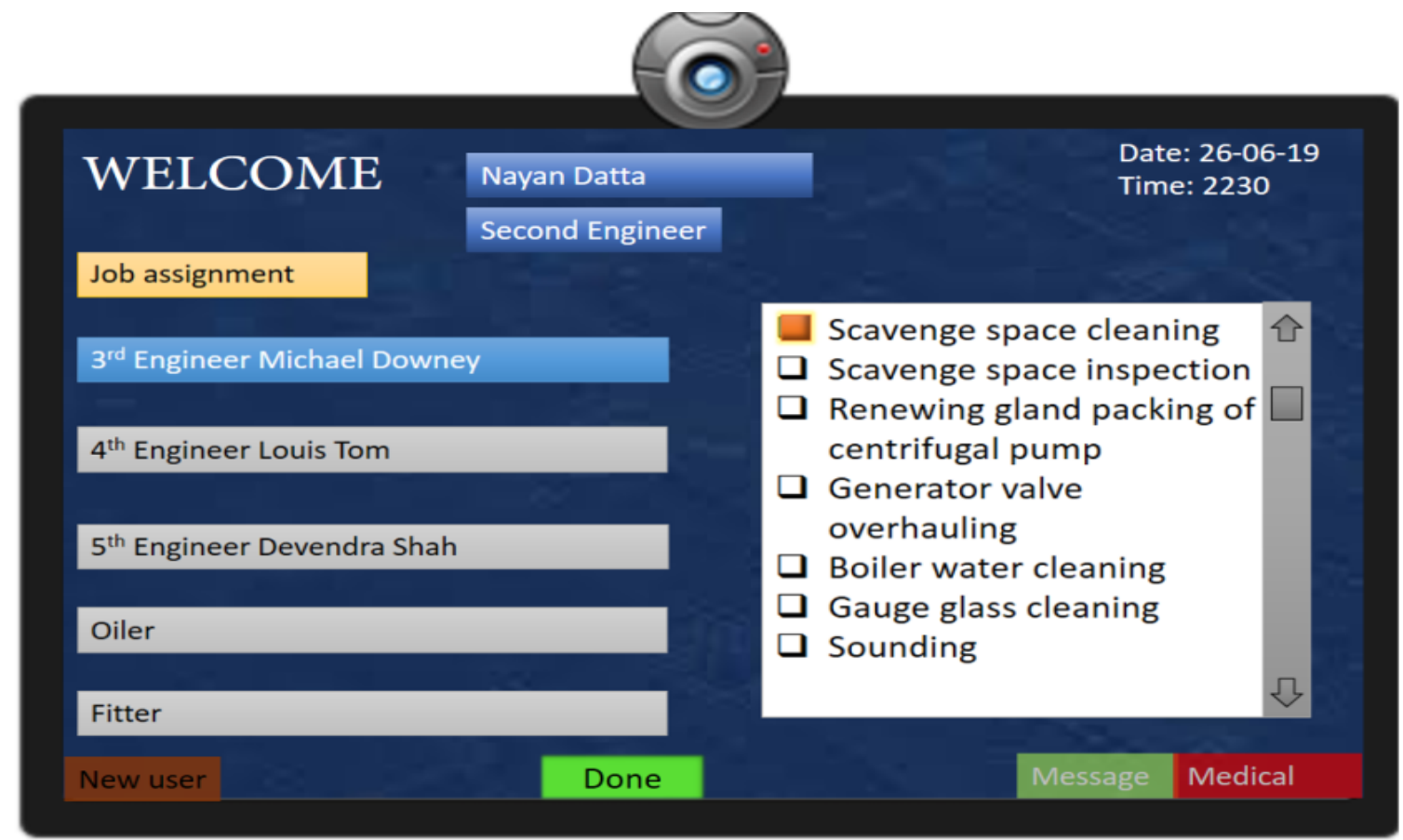

Figure 12. This screen will only be available to authorized personnel who will be able to assign tasks for the officers and crew below them by first selecting the name of the officer and then the tasks from the list of all possible tasks and after which he/she will press "Done".

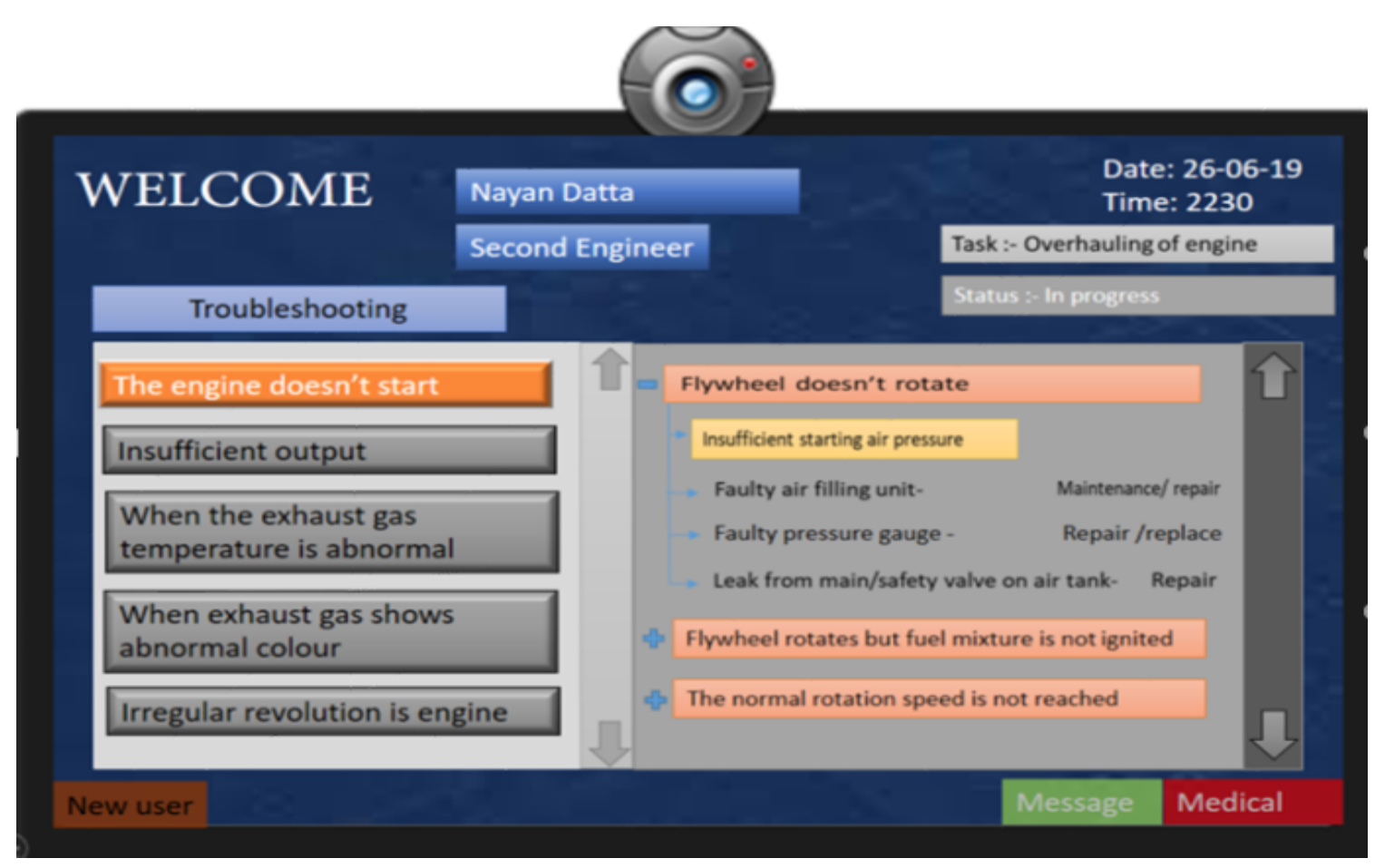

Figure 13 Troubleshooting solutions for various problems can be obtained from this screen. 


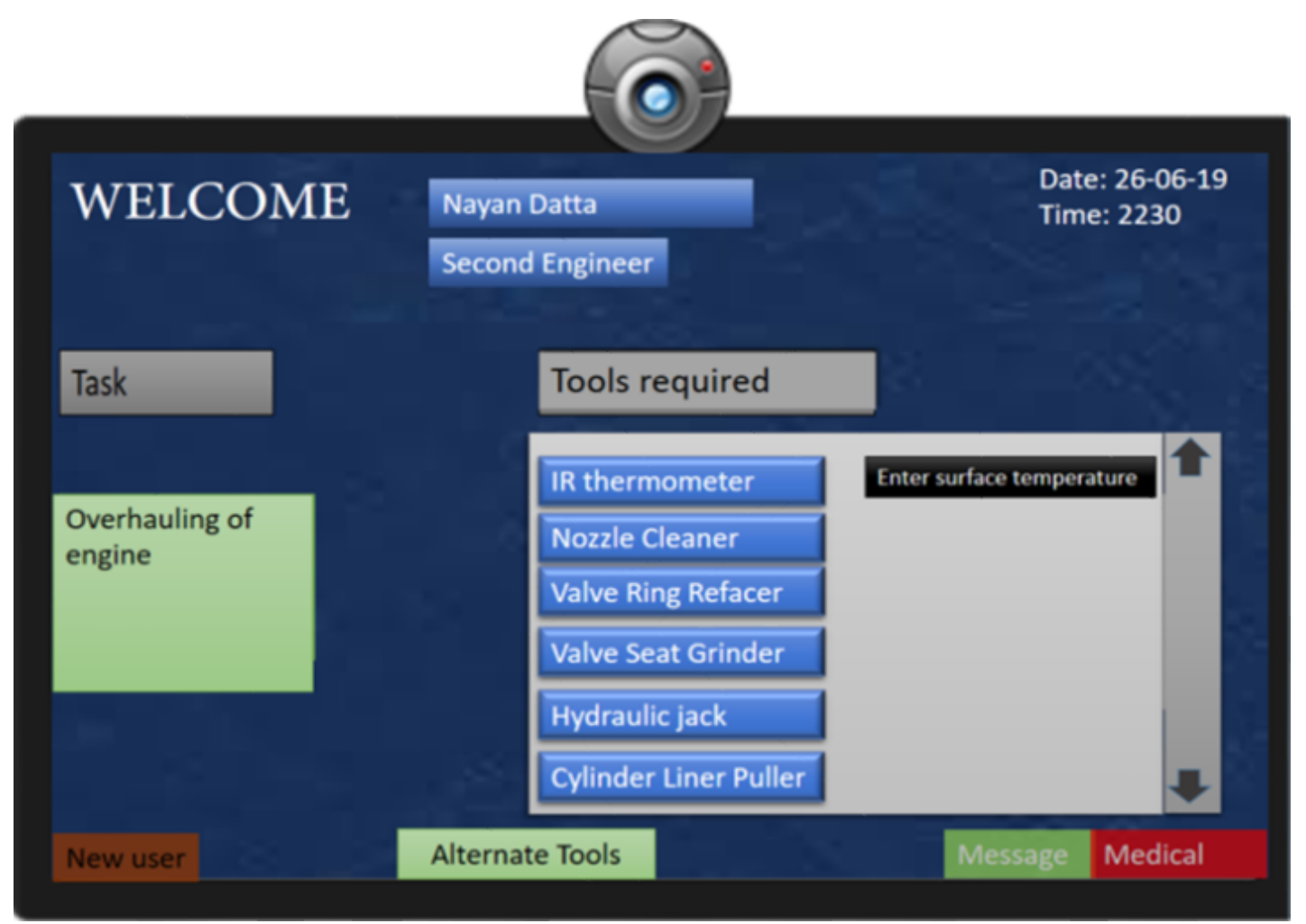

Figure 14 The list of required tools will be shown. The surface temperature of the machine will need to be entered here too. The system will have the entire information about the ship's inventory which will have to be updated if required.

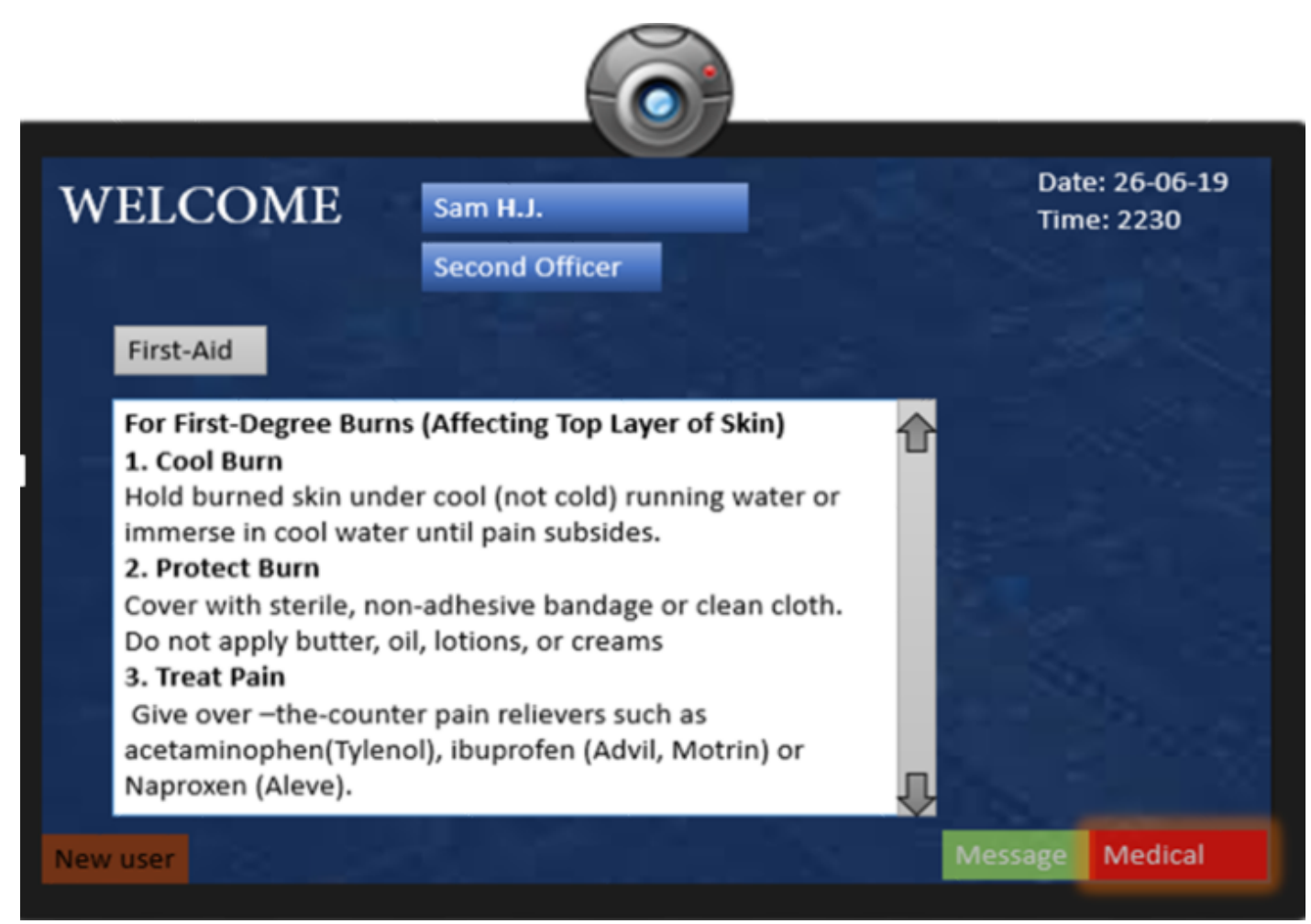

Figure 15 First Aid steps will also be available, if a person wants to view them 


\section{Conclusion}

The software promotes the ISM code in the following ways:

5.1. Since all the records of each job will be digitalized, the Designated Person will be able to keep check of the work. He will also be alerted if a person tries to proceed for a job with proper instructions or PPEs.

5.2. Having an Interactive software for planning and operation of jobs will help the crew to complete the job more efficiently.

5.3. Having an Interactive software for planning and operation of jobs will help the crew to complete the job more efficiently.

5.4. This will increase the Shipping Performance Indicators (SPI) which will help the shipping companies to file greater insurance claims like Protection and Indemnity (P\&I) Insurance.

5.5. SPI002 (Health and Safety Management Performance) is an expression of the organization's ability to effectively manage the health and safety of the personnel onboard. By using the software, the following KPI (Key Performance Indicators) will be altered in company's favor: -

- $\quad$ KPI017 Lost Time Injury Frequency

- KPI015 Health and Safety deficiencies

- KPI018 Lost Time Sickness Frequency

5.6. SPI007 (Technical Performance) is an expression based on company's ability to maintain the ship, minimize the number of condition of class and reduce failures of critical equipment and system. By using the software, the following KPI (Key Performance Indicators) will be altered in company's favor: -

- KPI012 Failure of critical equipment and systems

- Planned maintenance*

- Technical deficiencies*

*The Expert Group is considering to in the future to add two new KPIs

5.7. The troubleshooting function of the software will reduce the panic in emergency situation and will prevent allowing any accidents that would have been caused.

5.8. This will also help the company to claim insurance easily.

5.9. The reports forwarded to the designated person can be used to create an analysis report.

\section{Acknowledgements}

The author would like to thank Fleet Management Limited and Vulica Shipping Company for supporting and guiding us. Also we are thankful of Professor Shashank Bani of Indian Maritime University for helping us.

\section{References}

Kurt. (2019, May 22). Object Detection Tutorial in TensorFlow: Real-Time Object Detection. Retrieved June 30, 2019, from https://www.edureka.co/blog/tensorflow-object-detection-tutorial/

Safety and Shipping Review 2018. (2018, July 18). Retrieved June 15, 2019, from https://www.arctictoday.com/wpcontent/uploads/2018/07/AGCS_Safety_Shipping_Review_2018.pdf

ISM Code, IMO Publication, 2014 edition

The Shipping KPI Standard V3.0 2019 (2019, January 1).Retrieved March 20, 2020, from https://www.shippingkpi.org/public/downloads/documentation/Shipping_KPI_Standard_V3.0.pdf 